\title{
Hubungan Peran Tenaga Kesehatan, Pengetahuan dan Dukungan Suami dengan Akseptor KB IUD di UPTD Puskesmas Pengandonan Kabupaten Ogan Komering Ulu
}

\author{
Trianingsih ${ }^{1}$, Erma Puspita Sari ${ }^{2 *}$, Siti Aisyah Hamid ${ }^{3}$, Hasbiah $^{4}$ \\ ${ }^{1}$ Program Studi Kebidanan Universitas Kader Bangsa Palembang \\ ${ }^{2,3,4}$ Universitas Kader Bangsa, Jln HM Ryacudu No 887 Ulu Palembang Sumatera Selatan \\ Correspondence e-mail: ermapuspitasari88@gmail.com
}

\begin{abstract}
Abstrak. IUD adalah salah satu metode kontrasepsi yang memiliki efektivitas tinggi, kontrasepsi IUD dipasang didalam rahim. Faktor-faktor yang mempengaruhi akseptor KB IUD diantaranya peran tenaga kesehatan, pengetahuan, dukungan suami secara simultan di puskesmas pengandionan kab oku tahun 2021..Jenis penelitian ini adalah survei analitik dengan desain cross sectional. Populasi dalam penelitian ini adalah akseptor KB yang berkunjung ke puskesmas pengandonan dari bulan Juli-Agustus 2021 dengan sampel 38 responden dengan teknik pengambilan sampel accidental sampling. Instrumen penelitian ini adalah kuesioner, dengan analisis data univariat dan bivariat $(\alpha=95 \%)$. Hasil analisis di dapatkan dari 38 responden yang menggunakan KB IUD ( $23,7 \%$ ) dan peran tenaga kesehatan baik yang menggunakan KB IUD (15,8\%),pengetahuan baik menggunakan KB IUD (23,7\%) sedangkan yang ada dukungan suami pengguna KB IUD sebesar $(21,1 \%)$. Berdasarkan analisis bivariat hasil uji chi-square peran tenaga kesehatan ( $p$-value $=0,001$. pengetahuan ( vvalue $=0,002)$ dan dukungan suami ( vvalue $=0,000)$ kesimpulan ada hubungan peran tenaga kesehatan,pengetahuan dan dukungan suami di UPTD puskesmas pengandonan tahun 2021.saran untuk puskesmas Diharapkan bagi tenaga kesehatan lebih berperan aktif lagi dalam memberikan konseling serta penyuluhan di setiap kegiatan posyandu,membagikan lieflet pada setiap wanita usia subur yang berkunjung ke puskesmaas agar pengetahuan ibu menjadi baik
\end{abstract}

Kata kunci : Dukungan Suami; Pengetahuan; Peran Tenaga Kesehatan

Abstract. The IUD is one of the contraceptive methods that has a high effectiveness of IUD contraception installed in the uterus. Factors that affect IUD family planning acceptors include the role of health workers, knowledge, husband's support simultaneously at the pengandonan health center, Kab. Oku in 2021. This type of research is an analytical survey with a cross sectional design. The population in this study were family planning acceptors who visited the pengandonan health center from January to July 2021 totaling 247 people with a sample of 38 respondents using accidental sampling technique. The research instrument is a questionnaire, with univariate and bivariate data analysis $(\alpha=95 \%)$. The results of the analysis were obtained from 38 respondents who used IUD KB (23.7\%) and the role of health workers both who used IUD KB (15.8\%), good knowledge of using IUD KB (23.7\%) while those who were supported by husbands of users KB IUD by (21.1\%). Based on the bivariate analysis of the results of the chi-square test of the role of health workers $(p$-value $=0.001$. knowledge $(p$-value $=0.002)$ and husband's support ( $p$-value $=0.000$ ), it was concluded that there was a relationship between the role of health workers, knowledge and support of husbands in the UPTD of the pengandonan health center in 2021. Suggestions for puskesmas It is hoped that health workers will play an active role again in providing counseling and counseling in every posyandu activity, distributing lieflet to every woman of childbearing age who visits the puskesmas so that the mother's knowledge becomes good

Keywords: Husband's Support; Knowledge; Role of Health Workers

\section{PENDAHULUAN}

Kebijakan pemerintah tentang Keluarga Berencana mengarah pada pemakaian metode kontrasepsi jangka panjang.selain mengendalikan penduduk program keluarga berencana juga bermanfaat mewujudkan akses kesehatan reproduksi bagi semua masyarakat pada tahun 2030 seperti yang tercantum dalam Sustainable Development Goals (SDGs) indikator 3.7 yaitu Pada 2030, menjamin akses semesta kepada pelayanan kesehatan seksual dan reproduksi,termasuk keluarga berencana,informasi dan edukasi, serta integrasi kesehatan reproduksi ke dalam strategi dan program nasional. (Balitbangkes, 2013)

Di tingkat dunia tahun 2017 Prevalensi penggunaan kontrasepsi atau CPR (Contraceptive Pravelensi Rate) sebesar $63 \%$ dan telah meningkat di banyak bagian dunia terutama di Amerika Utara, Amerika Latin dan Karibia yaitu diatas $75 \%$ dan terendah di Afrika Sub-Sahara yaitu dibawah $36 \%$.Secara global, prevalensi penggunaan kontrasepsi modern telah meningkat tidak signifikan yaitu dari $35 \%$ tahun 1970 menjadi $58 \%$ pada tahun 2017,pada tahun 2030 di perkirakan penggunaan kontrasepsi meningkat terutama didaerah afrika dan Asia selatan. Di Afrika Barat akan meningkat dari $20 \%$ menjadi $29 \%$, di afrika timur dari $43 \%$ menjadi $56 \%$ dan $38 \%$ menjadi $43 \%$ di negara melanesia, mikronesia dan polinisia.(United Nation, department of economic and cocial affairs dan Population division 2017) (Harahap, 2019)

Data Profil Kesehatan Indonesia Tahun 2017 prevalensi penggunaan kontrasepsi di indonesia dengan cakupan KB aktif secara nasional sebesar suntik $(63,22$ 
Trianingsih., Hubungan Peran Tenaga Kesehatan, Pengetahuan dan Dukungan Suami dengan Akseptor KB IUD di UPTD Puskesmas Pengandonan Kabupaten Ogan Komering Ulu

$\%)$,Pil (17,24 \%), IUD (7,15\%), Implan (6,99\%), MOW (2,78 \%) ,Kondom (1,22 \%), MOP (0,53\%) Tahun 2018 cakupan peserta KB aktif menurut kontrasepsi modern suntik $(63,71 \%)$,Pil $(17,24 \%)$, IUD $(7,35 \%)$, Implan (7,2 \%), MOW (2,76 \%) ,Kondom (1,24\%), MOP (0,53 \%) sedangkan Pada Tahun 2019 cakupan peserta KB aktif menurut metode kontrasepsi modern suntik (63,71\%), Pil (17,0\%), IUD $(7,4 \%)$, Implan $(7,4 \%)$, MOW $(2,7 \%)$, Kondom $(1,2 \%)$, $\operatorname{MOP}(0,5 \%)$

Data Provinsi Sumatera Selatan Capaian CPR (Contraceptive Prevalence Rate) berdasarkan data statistic sebesar 1.402.046 (78,83\%) dari jumlah PUS sebanyak 1.778.618. Jika dibandingkan capaian CPR tahun 2018 sejumlah $1.357 .394(78,64 \%)$ dari jumlah PUS sebanyak 1.726.165, maka mengalami kenaikan sebesar $0,2 \%$. Tingginya pencapaian CPR ini sejalan dengan meningkatnya pencapaian peserta $\mathrm{KB}$ aktif Tahun 2019 sebesar 1.402.046 PUS $(137,44 \%)$ dari PPM sebesar 1.020.093 PUS. sedangkan Pencapaian Peserta KB Aktif Tahun 2018 sebesar $1.357 .394(132,17 \%)$ dari PPM 1.026.989 PUS.dengan rincian IUD 4,68\%,Implant 23,63\%,Suntik 42,57\%, Pil 21,34\%,Kondom 4,41\%, MOP 0,45\%, MOW 2,94\% Di Tahun 2019 IUD 4,61\%,Implant $\quad 23,61 \%$,Suntik $\quad 42,80 \%$,Pil $21,11 \%$,Kondom $\quad 4,48 \%$,MOP $\quad 0,43 \%$,MOW $2,96 \%$. (LAKIP Sumsel, 2019).

Data Dinkes OKU Tahun 2018 dengan jumlah PUS 60.526 orang peserta KB Aktif 50.589 (83.58\%) akseptor dengan kontrasepsi IUD 1768 orang $(2,92 \%)$ ,Implant 5932 orang $(9,80 \%)$,Pil 11571 orang $(19,11 \%)$ , Suntik 27936 orang $(46,15 \%)$,MOW 445 orang $(0.73 \%)$,MOP 88 orang $(0.14 \%)$ dan Kondom 2849 orang (4.70\%).Tahun 2019 jumlah PUS 61815 orang peserta KB Aktif 52486 (84,90\%) akseptor dengan kontrasepsi IUD 1897 orang $(3,06 \%)$,Implant 5855orang (9,47\%),Pil 12757 orang $(20,63 \%)$ Suntik 28568 orang $(46,21 \%)$,MOW 642 orang $(1,03 \%)$,MOP 95 orang $(0.15 \%)$ dan Kondom 2263 orang (3.66\%) dan Tahun 2020 jumlah PUS 63261 orang peserta KB Aktif $52536(83,04 \%)$ akseptor dengan kontrasepsi IUD 1916 orang (3,02\%) ,Implant 6697 orang (10,58\%),Pil 12805 orang $(20,24 \%)$, Suntik 28164 orang $(44,52 \%)$,MOW 465 orang $(0,73 \%)$,MOP 88 orang $(0,13 \%)$ dan Kondom 2401 orang (3.79\%) .

IUD ( Intra Uterine Device ) atau Alat kontrasepsi dalam rahim (AKDR) merupakan alat kontrasepsi terbuat dari plastik yang fleksibel di pasang didalam rahim.IUD salah satu jenis MKJP dimana pertimbangan alasan pemerintah lebih menganjurkan penggunaan MKJP karena lebih efisien dibanding Non MKJP,lebih efektif,tingkat kegagalan,efek samping dan komplikasi relatif rendah. (BKKBN, 2016 )

Faktor - Faktor yang mempengaruhi seorang ibu dalam memilih alat kontrasepsi dalam rahim, diantaranya adalah : Dukungan keluarga, peran petugas kesehatan, efek samping, sikap, paritas, umur, pendapatan, keluarga , pendidikan, pengetahuan. (Hartanto, 2013)

Data UPTD Puskesmas PengandonanTahun 2018 PUS berjumlah 1687 orang peserta KB aktif 1190 orang (70,53\%) dengan akseptor KB IUD 37 orang $(2,19 \%)$,Implant 246 orang (14,58\%),Pil 27 orang (1.60 $\%)$,Suntik 775 orang $(45,93 \%)$ MOW 49 orang $(2.90 \%)$, MOP 1 orang $(0.056 \%)$,Kondom 55 orang ( 3,26\%),Data Tahun 2019 PUS 1730 orang peserta KB aktif 1392 orang $(80,46 \%)$ dengan akseptor KB IUD 37 orang (2,13\%),Implant 246 orang (14,21\%),Pil 227 orang $(13,12 \%)$,Suntik 777 orang $(44,91 \%)$ MOW 49 orang (2.83\%), MOP 1 orang $(0.05 \%)$, Kondom 55 orang $(3,17 \%)$ dan Tahun 2020 PUS berjumlah 1.771 orang peserta $\mathrm{KB}$ aktif 1.677 orang $(94.70 \%)$ dengan akseptor KB IUD 57 orang (3.21\%),Implant 246 orang (13,89\%),Pil 326 orang(18.40 \%),Suntik 895 orang $(50.5 \%)$ MOW 39 orang $(2.20 \%)$, MOP 1 orang $(0.056 \%)$, Kondom 73 orang (4.12\%).Pada Tahun 2021 PUS 1.770 orang KB aktif 1.206 orang $(68,14 \%)$ Cakupan akseptor KB dari bulan januari - juli 2021 yaitu akseptor KB IUD 42 orang (2,37\%),Implant 230 orang (12,9\%),Pil 241 orang(13,6\%),Suntik 624 orang $(35,2 \%)$ MOW 19 orang $(1,07 \%)$, MOP 1 orang $(0.056 \%)$,Kondom 51 orang $(2,88 \%)$ (Profil Puskesmas, 2020)

Penelitian ini bertujuan untuk menidentifikasi hubungan peran tenaga kesehatan, pengetahuan dan dukungan suami dengan akseptor KB IUD

\section{METODE}

Penelitian ini adalah penelitian kuantitatif dengan menggunakan survey analitik dengan desain penelitian cross sectional, dimana yaitu penelitian yang diarahkan untuk menjelaskan suatu keadaan yang sifatnya hanya mengambil sebagian dari objek populasi / sampel dimana variabel sebab (peran tenaga kesehatan ,pengetahuan ,dan dukungan suami ) dan variabel akibat (Akseptor KB IUD ) di kumpulkan dalam waktu yang bersamaan (Notoatmodjo, 2018 )

Popuasi pada penelitian ini adalah Akseptor KB aktif yang berkunjung ke UPTD Puskesmas Pengandonan bulan Juli-Agustus Tahun 2021. Tehnik pegambilan sampel menggunakan teknik Accidental Sampling dimana penentuan sampel berdasarkan kebetulan ,yaitu siapa saja yang kebetulan bertemu dengan peneliti dapat digunakan sebagai sampel.bila di pandang orang yang kebetulan ditemui itu cocok sebagai sumber data (Sugiono,2013).

Penelitian ini telah memperoleh surat keterangan lolos kaji etik dari Komite Etik Penelitian Kesehtaan Fakultas Kesehatan Universitas Kader Bangsa Palembang dengan No:178/UKB.FKES/TU.KEPK/2021 Pengambilan data dilakukan selama empat minnggu pada bulan Juli-Agustus tahun 2021 dengan menggunakan lembar kuesioner. 
Trianingsih., Hubungan Peran Tenaga Kesehatan, Pengetahuan dan Dukungan Suami dengan Akseptor KB IUD di UPTD Puskesmas Pengandonan Kabupaten Ogan Komering Ulu

\section{HASIL DAN PEMBAHASAN \\ Analisis Univariat}

Hasil analisis univariat Akseptor KB IUD tergambar pada tabel 1 .

Tabel 1. Distribusi Frekuensi dan Persentase Responden Berdasarkan Akseptor KB IUD di UPTD Puskesmas Pengandonan Kabupaten OKU

\begin{tabular}{lcc}
\hline Akseptor KB IUD & Frekuensi (f) & Persentase (\%) \\
\hline Ya & 9 & 23,7 \\
Tidak & 29 & 76,3 \\
Total & $\mathbf{3 8}$ & $\mathbf{1 0 0}$
\end{tabular}

Sumber data: hasil penelitian

Berdasarkan Tabel 1 diketahu bahwa dari 38 responden wanita usia subur dengan Akseptor KB IUD sebesar 9 responden $(23,7 \%)$, dan wanita usia subur yang tidak menggunakan Akseptor KB IUD sebanyak 29 responden $(76,3 \%)$.

Hasil analisis univariat faktor peran tenaga kesehatan tergambar pada tabel 2 .

Tabel 2. Distribusi Frekuensi dan Persentase Responden

Berdasarkan peran tenaga kesehatan di UPTD Puskesmas Pengandonan Kabupaten OKU

\begin{tabular}{lcc}
\hline Peran Tenaga Kesehatan & Frekuensi (f) & Persentase (\%) \\
\hline Baik & 6 & 15,8 \\
Kurang & 32 & 84,2 \\
Total & $\mathbf{3 8}$ & $\mathbf{1 0 0}$
\end{tabular}

Sumber data: hasil penelitian

Berdasarkan Tabel 2 diketahu bahwa diketahui bahwa dari 38 responden peran tenaga kesehatan baik sebesar 6 responden (15.8\%), sedangkan peran tenaga kesehatan kurang sebanyak 32 responden $(84.2 \%)$.

Hasil analisis univariat faktor pengetahuan ibu tergambar pada tabel 3 .
Tabel 3. Distribusi Frekuensi dan Persentase Responden Berdasarkan pengetahuan ibu di UPTD Puskesmas Pengandonan Kabupaten OKU

\begin{tabular}{lcc}
\hline Pengetahuan ibu & Frekuensi (f) & Persentase (\%) \\
\hline Baik & 9 & 23,7 \\
Kurang & 29 & 76,3 \\
Total & $\mathbf{3 8}$ & $\mathbf{1 0 0}$ \\
& &
\end{tabular}

Sumber data: hasil penelitian

Berdasarkan Tabel 3 diketahu bahwa dari 38 responden dengan pengetahuan baik sebesar 9 responden $(23,7 \%)$, sedangkan dengan pengetahuan kurang sebanyak 29 responden $(76,3 \%)$

Hasil analisis univariat faktor Dukungan Suami tergambar pada tabel 4.

Tabel 4. Distribusi Frekuensi dan Persentase Responden Berdasarkan pengetahuan ibu di UPTD Puskesmas Pengandonan Kabupaten OKU

\begin{tabular}{lcc}
\hline Dukungan Suami & Frekuensi (f) & Persentase $(\%)$ \\
\hline Ya & 8 & 21,1 \\
Tidak & 30 & 78,9 \\
Total & $\mathbf{3 8}$ & $\mathbf{1 0 0}$
\end{tabular}

Sumber data: hasil penelitian

Berdasarkan Tabel 4 diketahu bahwa dari 38 responden yang mendapat dukungan suami sebesar 8 responden $(21,1 \%)$, sedangkan yang tidak mendapatkan dukungan suami sebesar 30 responden $(78,9 \%)$.

\section{Analisis Bivariat}

Analisis ini diakukan untuk mengetahui hubungan antara variabel dependen (akseptor KB IUD) dengan variabel independen (peran tenaga kesehatan,pengetahuan dan dukungan suami)

Hasil analisis bivariat hubungan Pengetahuan Ibu, sikap ibu dan dukungan keluarga dengan Kurangnya minat bersalin di Fasilitas Kesehatan dapat dilihat pada tabel 5.

Tabel 5. Hubungan Variabel Independen dan Variabel Dependen

\begin{tabular}{|c|c|c|c|c|c|c|c|c|c|}
\hline \multirow{3}{*}{ No } & \multirow{3}{*}{ Variabel Independen } & \multicolumn{4}{|c|}{ Akseptor KB IUD } & \multirow{2}{*}{\multicolumn{2}{|c|}{ Total }} & \multirow{3}{*}{$\begin{array}{c}P \\
\text { Value }\end{array}$} & \multirow{3}{*}{$\begin{array}{c}\text { Odd } \\
\text { Ratio } \\
95 \% \text { CI }\end{array}$} \\
\hline & & \multicolumn{2}{|c|}{ Ya } & \multicolumn{2}{|c|}{$\begin{array}{l}\text { Tidak } \\
\end{array}$} & & & & \\
\hline & & $\mathbf{n}$ & $\%$ & $\mathbf{n}$ & $\%$ & $\mathbf{N}$ & $\%$ & & \\
\hline \multirow[t]{3}{*}{1} & Peran Tenaga & & & & & & & & \\
\hline & $\begin{array}{l}\text { Kesehatan } \\
\text { 1. Baik }\end{array}$ & 5 & 83,3 & 1 & 16,7 & 6 & 100 & $\mathbf{0 , 0 0 1}$ & 35.00 \\
\hline & 2. Kurang & 4 & 12,5 & 28 & 87,5 & 32 & 100 & & \\
\hline \multirow[t]{3}{*}{2} & Pengetahuan Ibu & & & & & & & & \\
\hline & 1. Baik & 6 & 66,7 & 3 & 33,3 & 9 & 100 & $\mathbf{0 , 0 0 2}$ & 17,333 \\
\hline & 2. Kurang & 3 & 10,3 & 26 & 89,7 & 29 & 100 & & \\
\hline \multirow[t]{3}{*}{3} & Dukungan Suami & & & & & & & & \\
\hline & 1. $\mathrm{Ya}$ & 7 & 87,5 & 1 & 12,5 & 8 & 100 & 0,000 & 98.00 \\
\hline & 2. Tidak & 2 & 6,7 & 28 & 93,3 & 30 & 100 & & \\
\hline
\end{tabular}

Sumber data: hasil penelitian 
Berdasarkan tabel 5 hasil analisis hubungan peran tenaga kesehatan dengan Akseptor KB IUD diperoleh bahwa dari 6 responden yang peran tenaga kesehatan baik yang menggunakan KB IUD sebanyak 5 responden $(83,3 \%)$, sedangkan dari 32 peran tenaga kesehatan kurang 4 responden $(12,5 \%)$ yang menggunakan $\mathrm{KB}$ IUD. Hasil uji statistik diperoleh nilai $p$ value $=0,001 \leq$ $\alpha=0,05$ maka dapat disimpulkan bahwa ada hubungan yang signifikan peran tenaga kesehatan dengan Akseptor KB IUD di UPTD Puskesmas Pengandonan Muara Enim tahun 2021. Hasil analisis diperoleh nilai OR : 35.00 yang artinya responden yang mendapatkan peran tenaga kesehatan baik berpeluang 35,00 kali menggunakan KB IUD dibandingkan dengan responden yang kurang mendapat peran tenaga kesehatan.

Hasil Penelitian ini sejalan dengan penelitian yang di lakukan Risa Pitriani (2015) di wilayah kerja puskesmas Rawat Inap Muara Fajar Pekanbaru Tentang Hubungan pendidikan, pengetahuan dan peran tenaga kesehatan dengan penggunaan kontrasepsi Intra Uterine Device (IUD) dari 158 responden 77 responden $(48,7 \%)$ yang menilai peran tenaga kesehatan kurang,dimana hanya 1 responden $(1,3 \%)$ yang menggunakan IUD. dan 81 ( $51,3 \%)$ responden yang menilai peran tenaga kesehatan baik. ada $8 \quad(9,9 \%)$ responden yang menggunakan IUD.Dari hasil uji statistik terbukti Ada hubungan yang bemakna antara peran tenaga kesehatan dengan penggunaan kontrasepsi IUD dengan $(p$. value $=$ 0,034)

Menurut Kusumawati dkk 2013 bahwa peran tenaga kesehatan adalah suatu kegiatan yang diharapkan dari petugas kesehatan untuk memberikan pelayanan kesehatan pada masyarakat untuk meningkatkan derajat kesehatan masyarakat. pelayanan KB yang berkualitas merupakan unsur penting dalam upaya mencapai pelayanan kesehatan reproduksi salah satunya dengan pemberian informasi melalui KIE dengan KIE berarti bidan membantu calon akseptor untuk dapat menentukan jenis kontrasepsi yang terbaik untuk dirinya dan membantu akseptor KB dalam menggunakan kontrasepsinya lebih lama dan meningkatkan keberhasilan KB

Berdasarkan penelitian yang dilakukan di UPTD Puskesmas pengandonan sebagian ibu yang mendapat peran tenaga kesehatan dengan baik tetapi tidak mau menggunakan KB IUD dari hasil wawancara dengan responden maka peneliti berasumsi bahwa ibu tidak mau menggunakan KB IUD,karena adanya rasa malu pada saat pemasangan karena posisi pemasangan melalui organ vital,lalu dari sisi agama sebagian ibu berpendapat bahwa memasukan alat/benda asing kedalam tubuh tidak di perbolehkan secara syariat agama mengingat akan merepotkan ketika suatu hari sang ibu mengalami sesuatu yang tidak di inginkan misal kematian.masih adanya rasa takut seakan akan sakit dengan alat yang digunakan saat pemasangan.
Hasil analisis hubungan pengetahuan ibu ibu dengan Akseptor KB IUD diperoleh bahwa dari 9 responden yang pengetahuan baik 6 responden (66,7\%),yang mengunakan KB IUD sedangkan yang pengetahuan kurang 29 responden yang menggunakan KB IUD sebanyak 3 responden (10,3\%). Hasil uji statistik chi square diperoleh nilai $p$ value $=0,002 \leq \alpha=$ 0,05, maka dapat disimpulkan bahwa ada hubungan yang signifikan antara pengetahuan ibu dengan Akseptor KB IUD. Hasil analisis diperoleh nilai OR : 17.333 artinya responden yang berpengetahuan baik berpeluang 17,33 kali menggunakan KB IUD dibandingkan dengan responden yang berpengetahuan kurang.

Hasil penelitian sejalan dengan penelitian Rohaeni (2020) tentang faktor-faktor yang mempengaruhi penyebab rendahnya penggunaan alat kontrasepsi dalam rahim (AKDR) di Desa Grogol Kec Gunung Jati Kab Cirebon.dari 30 responden yang diteliti yang berpengetahuan baik dan memakai AKDR 9 (30\%) responden sedangkan $21 \quad(70 \%)$ responden yang berpengetahuan tidak baik dimana $1(3,3 \%)$ responden yang menggunakan AKDR .maka dari uji chi squere didapatkan hasil nilai $\mathrm{p}$ - value 0,000 atau $<0,05$ yang artinya ada hubungan yang bermakna antara pengetahuan dengan pengunaan alat kontrasepsi dalam rahim atau AKDR.

Pengetahuan merupakan hasil dari tahu dan ini terjadi setelah orang melakukan penginderaan terhadap objek tertentu. Pengetahuan akseptor KB yang baik tentang hakekat program KB akan mempengaruhi seseorang dalam memilih metode/alat kontrasepsi yang akan digunakannya termasuk keleluasaan atau kebebasan pilihan, kecocokan pilihan dan efektif tidaknya, kenyamanan dan keamanan, dalam memilih tempat pelayanan yang lebih sesuai dan lengkap karena wawasan sudah lebih baik, sehingga kesadaran mereka tinggi untuk terus memanfaatkan pelayanan. Pengetahuan Ibu tentang kontrasepsi AKDR/ IUD sangat berpengaruh terhadap pemakaian kontrasepsi AKDR/IUD (Notoatmodjo, 2012).

Berdasarkan penelitian yang dilakukan di UPTD Puskesmas pengandonan sebagian ibu yang berpengetahuan baik tidak mau menggunakan KB IUD maka adapun asumsi dari peneliti yaitu,biaya pemasangan yang relatif mahal terutama bagi ibu yang tidak memiliki jaminan kesehatan dan adanya pengalaman teman yang mengatakan bahwa adanya rasa tidak nyaman nyeri pada alat vital pria pada saat berhubungan seksual

Hasil analisis hubungan dukungan suami dengan Akseptor KB IUD diperoleh bahwa dari 8 responden yang mendapat dukungan suami $7(87,5 \%)$, responden yang menggunakan KB IUD.sedangkan yang tidak mendapatkan dukungan suami 30 responden dengan akseptor KB IUD sebanyak 2 responden $(6,7 \%)$. Hasil uji statistik chi square diperoleh nilai $p$ value $=0,000 \leq$ 
Trianingsih., Hubungan Peran Tenaga Kesehatan, Pengetahuan dan Dukungan Suami dengan Akseptor KB IUD di UPTD Puskesmas Pengandonan Kabupaten Ogan Komering Ulu

$\alpha=0,05$, maka dapat disimpulkan bahwa ada hubungan yang signifikan antara dukungan suami dengan Akseptor KB IUD. Hasil analisis diperoleh nilai OR : 98.00 artinya responden yang mendapatkan dukungan suami berpeluang 98.00 kali untuk menggunakan KB IUD di bandingkan dengan responden yang tidak mendapat dukungan suami.

Hasil penelitian ini sejalan dengan penelitian Hasil penelitian inipun sejalan dengan penelitian yang dilakukan oleh Novita (2020) Tentang Hubungan dukungan suami dengan pemilihan alat kontrasepsi dalam rahim (AKDR) pada wanita usia subur di Desa Wates Selatan Kecamatan Gading Rejo Kabupaten Pringsewu. Ia menyatakan bahwa dari hasil uji statistik ada hubungan yang bermakna antara dukungan suami dengan pemilihan AKDR dengan p-value 0,003.

Menurut Sulistyawati, 2012 bahwa dukungan suami merupakan salah satu faktor penguat yang dapat mempengaruhi seseorang berperilaku. Maka setiap dilakukan tindakan medis dalam penggunaan kontrasepsi, harus membutuhkan partisipasi atau dukungan suami karena menyangkut organ reproduksi dari kedua pihak.

Berdasarkan penelitian yang dilakukan di UPTD Puskesmas pengandonan sebagian ibu yang mendapat dukungan suami tetapi tidak menggunakan KB IUD asumsi dari peneliti karena keterbatasan pengetahuan ibu tentang KB IUD,ibu merasa ragu, cemas apabila alat yang dimasukkan kedalam rahim tadi lepas dan keluar bersama darah menstruasi.tanpa di ketahui yang akibatnya menimbulkan kehamilan pada ibu.

\section{SIMPULAN}

Hasil analisis menunjukkan bahwa peran tenaga kesehatan (p.value 0,001), pengetahuan ibu (p.value 0,002 ) dan dukungan suami (p.value 0,000) memiliki hubungan signifikan dengan Akseptoe KB IUD di UPTD Puskesmas Pengandonan. Hasil analisis diperoleh diperoleh nilai OR : 35.00 yang artinya responden yang mendapatkan peran tenaga kesehatan baik berpeluang 35,00 kali menggunakan KB IUD dibandingkan dengan responden yang kurang mendapat peran tenaga kesehatan, faktor pengetahuan ibu diperoleh nilai OR : 17.333 artinya responden yang berpengetahuan baik berpeluang 17,33 kali menggunakan KB IUD dibandingkan dengan responden yang berpengetahuan kurang dan faktor dukungan suami diperoleh nilai OR : 98.00 artinya responden yang mendapatkan dukungan suami berpeluang 98.00 kali untuk menggunakan KB IUD di bandingkan dengan responden yang tidak mendapat dukungan suami.

\section{DAFTAR PUSTAKA}

Balitbangkes, 2013. Riset Kesehatan Dasar. Jakarta: Kementerian Kesehatan

BKKBN Provinsi Sumatera Selatan. 2019, Laporan Akuntabilitas Kinerja Instansi Pemerintah.
BKKBN, 2016.Kebijaksanaan Program Kependudukan Keluarga Berencana Dan Pembangunan Keluarga: Jakarta : BKKBN

Harahap, Y. W., Hairani, N., \& Dewi, S.S.S. (2019). Hubungan Dukungan Suami dan Umur Akseptor KB Dengan Pemakaian Metode Kontrasepsi IUD. Jurnal Kesehatan Ilmiah Indonesia (Indonesian Health Scientific Journal), 4(2), 29-36.

Hartanto, H. 2013. Keluaga Berencana Dan Kontrasepsi. Sinar Harapan: Jakarta.

Kusumawati dkk, 2013.Buku Ajar Keperawatan Jiwa. Jakarta : Salemba Medika

Notoadmodjo. 2018, Metodologi Penelitian Kesehatan, Rineka Cipta: Jakarta

Notoadmodjo. 2012. Metodologi Penelitian Kesehatan, Rineka Cipta: Jakarta

Novita, Y., Qurniasih, N., Fauziah, N.A., \& Pratiwi, A.R. (2020). Hubungan Dukungan Suami dengan Pemilihan Alat Kontrasepsi dalam Rahim (AKDR) Pada Wusdi Desa Wates Selatan Kecamatan Gadingrejo Kabupaten Pringsewu Tahun 2020. Jurnal Maternitas Aisyah (JAMANAISYAH), 1(3), 172-181.

Pitriani, R. (2015). Hubungan pendidikan, pengetahuan dan peran tenaga kesehatan dengan penggunaan kontrasepsi Intra Uterine Device (IUD) diwilayah kerja Puskesmas Rawat Inap Muara Fajar Pekanbaru. Jurnal Kesehatan Komunitas, 3(1), 25-28.p

Profil Puskesmas Pengandonan Tahun 2020.

Rohaeni, E., \& Iis,I. (2020). Faktor-Faktor yang Mempengaruhi Penyebab Rendahnya Penggunaan Alat Kontrasepsi dalam Rahim (IUD) Di Desa Grogol Kec. Gunungjati. Syntax Literate; Jurnal Ilmiah Indonesia, 5(12), 1549-1565.

Sulistyawati, A. 2012. Pelayanan Keluarga Berencana. Jakarta: Salemba Medika

Sugiono. 2013. Metode Penelitian Kuantitatif, Kualitatif dan $R \& D$. Bandung: Alfabeta CV 